\title{
A narrative review on trans-nasal pulmonary aerosol delivery
}

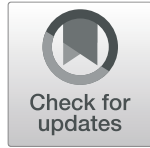

Jie Li $i^{*}$ D , James B. Fink ${ }^{1,2}$, Ronan MacLoughlin ${ }^{3}$ and Rajiv Dhand ${ }^{4}$

\begin{abstract}
The use of trans-nasal pulmonary aerosol delivery via high-flow nasal cannula (HFNC) has expanded in recent years. However, various factors influencing aerosol delivery in this setting have not been precisely defined, and no consensus has emerged regarding the optimal techniques for aerosol delivery with HFNC. Based on a comprehensive literature search, we reviewed studies that assessed trans-nasal pulmonary aerosol delivery with HFNC by in vitro experiments, and in vivo, by radiolabeled, pharmacokinetic and pharmacodynamic studies. In these investigations, the type of nebulizer employed and its placement, carrier gas, the relationship between gas flow and patient's inspiratory flow, aerosol delivery strategies (intermittent unit dose vs continuous administration by infusion pump), and open vs closed mouth breathing influenced aerosol delivery. The objective of this review was to provide rational recommendations for optimizing aerosol delivery with HFNC in various clinical settings.
\end{abstract}

Keywords: High-flow nasal cannula, Aerosol therapy, Asthma, Chronic obstructive pulmonary disease, Pulmonary hypertension, Oxygen therapy, Jet nebulizer, Vibrating mesh nebulizer

\section{Introduction}

In severely hypoxemic patients, supplemental oxygen is routinely administered by high-flow nasal cannula (HFNC). HFNC is superior to conventional oxygen therapy in improving oxygenation and ultimately for avoiding intubation/ reintubation in acutely ill patients [1-5]. Trans-nasal pulmonary aerosol delivery by HFNC combines the benefits of both HFNC and aerosol therapy [6, 7]. Since 2008, in vitro and in vivo studies have explored factors influencing delivery of aerosol with HFNC and the clinical effectiveness of this route of administration. In this article, we review the available evidence and provide a scientific basis for optimizing aerosol delivery with HFNC in various clinical settings.

\section{Literature search strategy and results}

A search of the published English literature was conducted in PubMed, Medline, and Scopus until February

\footnotetext{
* Correspondence: Jie_Li@rush.edu

'Division of Respiratory Care, Department of Cardiopulmonary Sciences, Rush University Medical Center, 1620 W Harrison St, Tower LL1202, Chicago, IL 60612, USA

Full list of author information is available at the end of the article
}

of 2020, using the following keywords: ("high-flow nasal cannul" OR "high flow cannul" OR "high flow oxygen therapy" OR "high flow oxygen" OR "high flow therapy" OR "HFNC" OR "trans-nasal") AND ("aerosol" OR "nebuliz" OR "inhal"”). Publication types included in vitro/ bench studies, scintigraphy studies for animal or healthy volunteers, clinical retrospective and prospective studies, randomized controlled trials, and questionnaire surveys. In total, databases identified 620 records and 42 original studies investigating aerosol delivery with HFNC were finally included. Articles were excluded for the following reasons: duplicates (153), did not investigate aerosol delivery via HFNC (415), conference abstracts (10), review articles (6), and letters (4).

\section{Clinical evidence of trans-nasal aerosol delivery}

Trans-nasal aerosol delivery is increasingly employed in the intensive care units (ICUs). A survey of pediatric units in the USA reported that $75 \%$ of respondents employed trans-nasal aerosol delivery, while the remainder discontinued HFNC and used more conventional 
methods for delivering aerosols [8]. While demonstrating the popularity of aerosol delivery via HFNC in children, the survey also revealed concerns about its clinical efficacy. In Table 1 , we summarize current clinical evidence regarding aerosol delivery with HFNC.

\section{Adult patients: inhaled albuterol delivery via HFNC}

In 2018, Bräunlich and colleagues reported that 26 patients with stable chronic obstructive pulmonary disease (COPD), who inhaled $2.5 \mathrm{mg}$ albuterol and $0.5 \mathrm{mg}$ ipratropium via a small volume jet nebulizer (JN) and mouthpiece or in-line with HFNC (TNI medical AG, Wuerzburg, Germany) at a gas flow of
$35 \mathrm{~L} / \mathrm{min}$, had similar bronchodilator effect $(p=0.5)$ [9]. Likewise, Réminiac and colleagues compared delivery of $2.5 \mathrm{mg}$ albuterol with a vibrating mesh nebulizer (VMN) (Aerogen Solo, Aerogen, Ireland) via HFNC (Airvo2, Fisher \& Paykel, New Zealand) versus a JN with mask in a cross-over RCT in 25 stable patients with reversible airflow obstruction and reported similar improvements in forced expiratory volume in the first second $\left(\mathrm{FEV}_{1}\right)(p=0.11)$ [10]. In a crossover RCT with 12 stable COPD patients, Madney and colleagues compared systemic bioavailability of albuterol administered by JN or VMN in line with HFNC at 5 $\mathrm{L} / \mathrm{min}$. Urinary albuterol excretion at $30 \mathrm{~min}$ and $24 \mathrm{~h}$

Table 1 Clinical studies using trans-nasal aerosol delivery via HFNC in adults and children

\begin{tabular}{|c|c|c|c|c|c|}
\hline Author, year & Study type & Patient & $\begin{array}{l}\text { Inhaled } \\
\text { medication }\end{array}$ & Comparison & Finding \\
\hline $\begin{array}{l}\text { Bräunlich and } \\
\text { Wirtz } 2018 \text { [9] }\end{array}$ & RCT crossover & Adults: 26 stable COPD & $\begin{array}{l}\text { Salbutamol } \\
2.5 \mathrm{mg}+ \\
\text { ipratropium } \\
0.5 \mathrm{mg}\end{array}$ & $\begin{array}{l}\text { JN via HFNC at } 35 \mathrm{~L} / \mathrm{min} \\
\text { vs JN alone }\end{array}$ & $\begin{array}{l}\mathrm{FEV}_{1} \text { change: } 9.4 \pm 13.6 \mathrm{vs} \\
11.1 \pm 17.2 \%, p=0.5\end{array}$ \\
\hline $\begin{array}{l}\text { Réminiac et al., } \\
2018 \text { [10] }\end{array}$ & RCT crossover & $\begin{array}{l}\text { Adults: } 25 \text { stable patients } \\
\text { with reversible airflow } \\
\text { obstruction }\end{array}$ & $\begin{array}{l}2.5 \mathrm{mg} \\
\text { albuterol }\end{array}$ & $\begin{array}{l}\text { VMN via HFNC at } 30 \mathrm{~L} / \mathrm{min} \\
\text { vs JN with mask }\end{array}$ & $\begin{array}{l}\text { FEV }{ }_{1} \text { improvement: } 0.33 \\
(0.14,0.39) \text { vs } 0.35(0.18 \\
0.55) L, p=0.11\end{array}$ \\
\hline $\begin{array}{l}\text { Madney et al., } \\
2019 \text { [11] }\end{array}$ & RCT crossover & Adults: 12 stable COPD & $\begin{array}{l}5 \mathrm{mg} \\
\text { salbutamol }\end{array}$ & $\begin{array}{l}\text { VMN via HFNC at } 5 \mathrm{~L} / \mathrm{min} \\
\text { vs } J N \text { via HFNC }\end{array}$ & $\begin{array}{l}\text { Urinary salbutamol excretion } \\
\text { at } 30 \text { min and } 24 \text { h were } \\
\text { higher with VMN than JN } \\
\text { via HFNC }(p<0.05)\end{array}$ \\
\hline $\begin{array}{l}\text { Li et al., } \\
2019[12]\end{array}$ & $\begin{array}{l}\text { Prospective dose } \\
\text { response study }\end{array}$ & $\begin{array}{l}\text { Adults: } 42 \text { stable asthma } \\
\text { and COPD patients }\end{array}$ & $\begin{array}{l}\text { Albuterol at an } \\
\text { escalating dose } \\
\text { of } 0.5,1.5,3.5 \text {, } \\
\text { and } 7.5 \mathrm{mg}\end{array}$ & $\begin{array}{l}\text { VMN via HFNC at } 15-20 \mathrm{~L} / \mathrm{min} \\
\text { vs MDI+Spacer }\end{array}$ & $\begin{array}{l}\mathrm{FEV}_{1} \text { increment at cumulative } \\
\text { dose of } 1.5 \mathrm{mg} \text { via HFNC was } \\
\text { similar to } 400 \mathrm{mcg} \text { albuterol } \\
\text { via MDI+Spacer: } 0.34 \pm 0.18 \text { vs. } \\
0.34 \pm 0.12 \mathrm{~L}, p=0.878\end{array}$ \\
\hline $\begin{array}{l}\text { Ammar et al., } \\
2018 \text { [13] }\end{array}$ & Retrospective & $\begin{array}{l}\text { Adults: } 29 \text { patients with } \\
\text { hypoxemia and } \mathrm{PH}\end{array}$ & Epoprostenol & VMN via HFNC at $39 \pm 11 \mathrm{~L} / \mathrm{min}$ & $\begin{array}{l}\mathrm{PaO}_{2} / \mathrm{F}_{1} \mathrm{O}_{2} \text { improvement of } \\
60 \pm 50 \mathrm{mmHg}\end{array}$ \\
\hline $\begin{array}{l}\text { Li et al., } \\
2019[14]\end{array}$ & Retrospective & $\begin{array}{l}\text { Adults: } 11 \text { ICU refractory } \\
\text { hypoxemia patients } \\
\text { comorbid with } \mathrm{PH} \text { and } \\
\text { /or RVD }\end{array}$ & Epoprostenol & VMN via HFNC at $35-40 \mathrm{~L} / \mathrm{min}$ & $\begin{array}{l}45.5 \% \text { had } \mathrm{SpO}_{2} / \mathrm{F}_{1} \mathrm{O}_{2} \text { improvement } \\
>20 \%\end{array}$ \\
\hline $\begin{array}{l}\text { Li et al., } \\
2020[15]\end{array}$ & $\begin{array}{l}\text { Retrospective } \\
\text { Cohort comparison }\end{array}$ & $\begin{array}{l}\text { Adults: } 51 \text { ICU patients } \\
\text { with } \mathrm{PH} \text { and/or RVD }\end{array}$ & Epoprostenol & $\begin{array}{l}\text { VMN via HFNC at constant flow } \\
(n=26) \text { vs flow titrated based on } \\
\text { individual response to inhaled } \\
\text { epoprostenol }(n=25)\end{array}$ & $\begin{array}{l}\text { The percentage of patients who met the } \\
\text { criteria for a positive response was } \\
\text { higher in the flow titration group } \\
\text { compared to the group with } \\
\text { constant flow ( } 85.7 \% \text { vs. } 50 \%, p=0.035) \text {. }\end{array}$ \\
\hline $\begin{array}{l}\text { Morgan et al., } \\
2015[16]\end{array}$ & Retrospective & $\begin{array}{l}\text { Pediatrics: } 5 \text { infants } \\
\text { acute bronchiolitis } \\
\text { with respiratory distress }\end{array}$ & Albuterol & $\begin{array}{l}\text { VMN via HFNC at } 5-8 \mathrm{~L} / \mathrm{min} \text { vs } \\
\mathrm{JN} \text { and face mask }\end{array}$ & $\begin{array}{l}\text { Compared to JN with mask, HR } \\
\text { increment was higher after inhaling } \\
\text { albuterol with VMN via HFNC; patient } \\
\text { agitation was improved }\end{array}$ \\
\hline $\begin{array}{l}\text { Valencia-Ramos } \\
\text { et al., } 2018 \text { [17] }\end{array}$ & RCT crossover & $\begin{array}{l}\text { Pediatrics: } 6 \text { infants } \\
\text { with bronchiolitis }\end{array}$ & Albuterol & $\begin{array}{l}\text { VMN via HFNC around } 8 \mathrm{~L} / \mathrm{min} \\
\text { vs JN with mask }\end{array}$ & $\begin{array}{l}\text { Increased level of comfort and } \\
\text { satisfaction }\end{array}$ \\
\hline $\begin{array}{l}\text { Al-Subu et al., } \\
2020[18]\end{array}$ & Retrospective & $\begin{array}{l}\text { Pediatrics: } 28 \text { children } \\
\text { with asthma or } \\
\text { bronchiolitis }\end{array}$ & Albuterol & $\begin{array}{l}\text { VMN via HFNC at } 2-4 \mathrm{~L} / \mathrm{min} \\
\text { vs VMN with mask }\end{array}$ & $\begin{array}{l}\text { HR increased by } 9.98(95 \% \mathrm{Cl} 3.72-16.2) \\
\text { with VMN via HFNC vs } 0.64(95 \% \mathrm{Cl} \text {, } \\
1.65-2.93) \text { beats/min with VMN via } \\
\text { mask }(p<0.001)\end{array}$ \\
\hline $\begin{array}{l}\text { Baudin et al., } \\
2017 \text { [19] }\end{array}$ & Retrospective & $\begin{array}{l}\text { Pediatrics: } 39 \text { status } \\
\text { asthmaticus ( } 10 \text { had } \\
\text { severe acidosis at } \\
\text { admission) }\end{array}$ & Albuterol & $\begin{array}{l}\text { VMN via HFNC at maximum } \\
1 \mathrm{~L} / \mathrm{kg} / \mathrm{min} \text { vs standard oxygen } \\
\text { without HFNC }\end{array}$ & $\begin{array}{l}\text { In HFNC group, HR }(165 \pm 21 \text { vs. } 141 \\
\pm 25 / \mathrm{min}, p<0.01) \text { and } \mathrm{RR}(40 \pm 13 \\
\text { vs. } 31 \pm 8 / \mathrm{min}, p<0.01) \text { decreased, } \\
\text { and blood gas improved in the first } 24 \mathrm{~h}\end{array}$ \\
\hline
\end{tabular}

HFNC high-flow nasal cannula, $J N$ jet nebulizer, $F E V_{1}$ forced expiratory volume at the first second, COPD chronic obstructive pulmonary disease, $M D I$ metered dose inhaler, $R C T$ randomized controlled trial, VMN vibrating mesh nebulizer, $P H$ pulmonary hypertension, $R V D$ right ventricular dysfunction, $H R$ heart rate, $R R$ respiratory rate, $\mathrm{PaO}_{2}$ partial pressure of arterial oxygen, $\mathrm{SpO}_{2}$ peripheral capillary oxygen saturation, $\mathrm{F}_{1} \mathrm{O}_{2}$ fraction of inspired oxygen, $\mathrm{Cl}$ confidence interval 
was 2-fold higher with the VMN than the JN $(p<$ 0.05) [11].

The label dose of albuterol solution in the USA and Europe is $2.5 \mathrm{mg}$. Li and co-workers performed a doseresponse relationship study in 42 stable asthma and COPD patients with known positive responses to 400 mcg albuterol via metered dose inhaler (MDI) and spacer. The subjects inhaled escalating doubling doses via VMN and HFNC with gas flow of $15-20 \mathrm{~L} / \mathrm{min}$. The improvement of $\mathrm{FEV}_{1}$ at the cumulative dose of $1.5 \mathrm{mg}$ with VMN and HFNC was similar to that with MDI and spacer $(p=0.878)$ (Fig. 1) [12].

\section{Adult patients: inhaled epoprostenol delivery via HFNC}

Inhaled epoprostenol, a pulmonary vasodilator, has been used off-label for several decades to treat mechanically ventilated patients with pulmonary hypertension and/or refractory hypoxemia [20,21]. In two small retrospective studies, adult patients with pulmonary hypertension and refractory hypoxemia improved oxygenation after inhaling epoprostenol via HFNC at an average gas flow of 40 L/min $[13,14]$. Mean pulmonary arterial pressure was reduced more effectively by titrating HFNC gas flow based on individual response to inhaled epoprostenol at the bedside compared with a constant HFNC flow [15].
Future prospective studies with larger sample size are needed to validate these findings.

\section{Pediatric patients: inhaled albuterol delivery via HFNC}

In 2015, Morgan and colleagues studied five infants with acute bronchiolitis and respiratory distress unresponsive to three treatments with JN via mask [16]. After inhaling albuterol via VMN and HFNC, infants appeared markedly more comfortable, suggesting that albuterol administration with HFNC was beneficial. An observed increase in heart rate probably reflected delivery of a higher albuterol dose via VMN and HFNC. Likewise, in children receiving albuterol by VMN via HFNC with flow at $2-4 \mathrm{~L} / \mathrm{min}$ or via face mask, the heart rates increased by 10 beats/min after inhaling albuterol via HFNC $(p<$ 0.001 vs mask) [18]. In a cross-over RCT in 6 infants with bronchiolitis, albuterol delivery via VMN with HFNC $(\sim 8 \mathrm{~L} / \mathrm{min})$ improved patients' comfort and satisfaction with treatment compared to JN and mask [17].

In a retrospective study of 39 children with status asthmaticus (10 had severe acidosis with $\mathrm{pH}<7.30$ ) who failed $\geq 3$ treatments with nebulized albuterol via $\mathrm{JN}$, intermittent boluses of albuterol delivered via

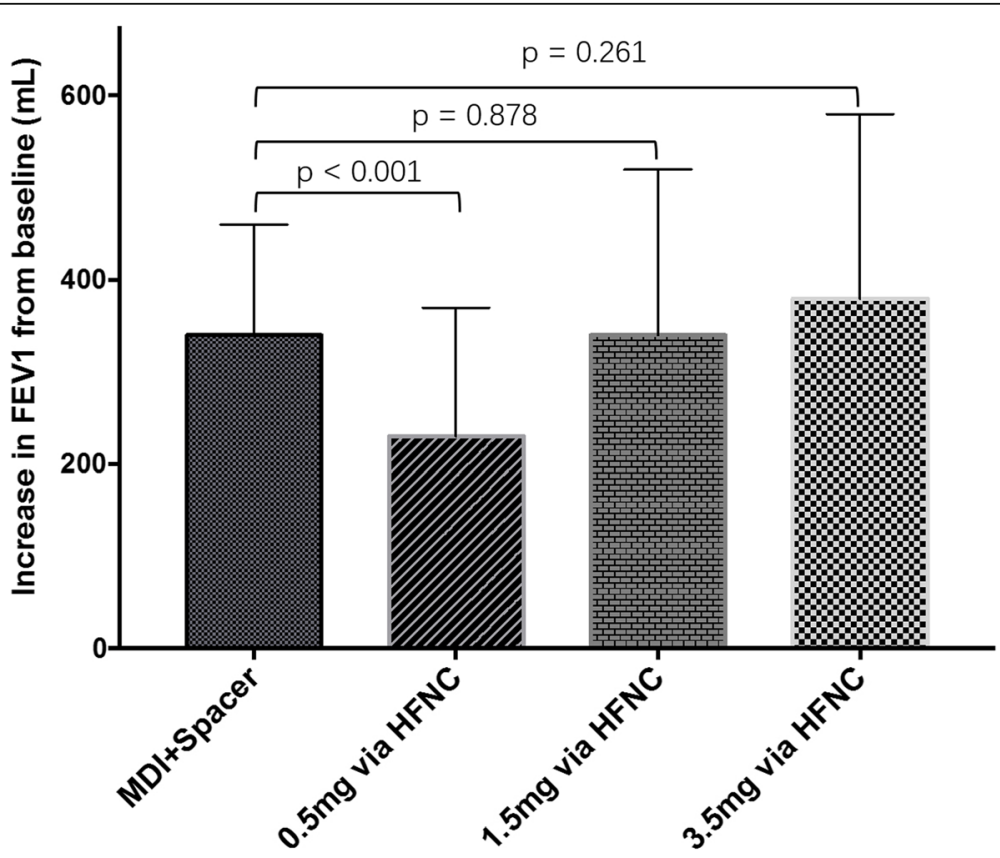

Aerosol delivery device and nominal dose

Fig. 1 Improvement in $\mathrm{FEV}_{1}(\mathrm{~mL})$ from baseline after inhalation of $400 \mathrm{mcg}$ albuterol via MDI with spacer or doubling doses of albuterol via VMN with HFNC (cumulative doses of 0.5, 1.5, and $3.5 \mathrm{mg}$ ). Figure modified from reference [12]. In 42 bronchodilator responsive patients with asthma or COPD, FEV 1 improvement after administration of $400 \mathrm{mcg}$ albuterol via $\mathrm{MDI}$ and spacer was higher than that after inhalation of $0.5 \mathrm{mg}$ albuterol via VMN with HFNC, but similar to that observed after inhalation of cumulative doses of $1.5 \mathrm{mg}$ or $3.5 \mathrm{mg}$ of albuterol via VMN with HFNC. COPD, chronic obstructive pulmonary disease; MDI, metered dose inhaler; FEV ${ }_{1}$, forced expiratory volume in the first second; $\mathrm{VMN}$, vibrating mesh nebulizer; HFNC, high-flow nasal cannula 
HFNC at a maximum flow of $1.0[0.8-1.1] \mathrm{L} / \mathrm{kg} / \mathrm{min}$ were considered as a contributor in avoiding intubation [19].

\section{Summary}

The standard bronchodilator doses delivered via HFNC at $15-35 \mathrm{~L} / \mathrm{min}$ for adults and $1 \mathrm{~L} / \mathrm{kg} / \mathrm{min}$ for children generated similar clinical responses to those delivered with conventional aerosol devices. Further studies need to quantify aerosol delivery efficiency in critically ill patients.

\section{Factors influencing trans-nasal aerosol delivery}

Since 2008, 18 in vitro [22-39] and 4 in vivo scintigraphy studies [38, 40-42] investigated factors influencing aerosol delivery via HFNC.

\section{Aerosol generator: VMN vs JN}

When a JN is placed in-line with HFNC, the total gas flow in the HFNC system is greater than $6 \mathrm{~L} / \mathrm{min}$, which is the minimal flow to operate the JN. This flow requirement limits the use of JN via HFNC for infants and small children, who require HFNC flow $\leq 6 \mathrm{~L} / \mathrm{min}$. Moreover, JN integrated into a HFNC system may be contraindicated in systems that incorporate their own flow generators (e.g., Airvo 2 from Fisher \& Paykel) as it alters oxygen, total flow, and pressure. In contrast, VMNs are driven by electricity with no additional gas flow required. Additionally, the residual volume of drug remaining in nebulizers is higher in JN than VMN $(45 \%$ vs $3 \%)[41,43]$. Consequently, VMN generated $2-3$ times higher inhaled dose than JN via HFNC for both pediatric and adult populations (Table 2) [11, 33, 38, 41]. For these reasons, VMNs are preferred over JNs for aerosol delivery with HFNC [8].

\section{Aerosol carrier}

HFNC gas functions as the "carrier" for aerosol, so that gas flow rate, gas density, and humidity could affect aerosol delivery efficiency.

\section{HFNC gas flow and patient's inspiratory flow}

In patients receiving HFNC therapy, the total inhalation flow is a combination of the patient's inspiratory flow and HFNC gas flow. The contribution of each flow influences the efficiency of aerosol delivery. When VMN was utilized to deliver aerosol via HFNC during quiet breathing, aerosol deposition was inversely related to the gas flow (Table 3) [23, 26, 27, 33, 38, 40, 42, 44]. Turbulence generated with higher gas flow leads to greater impaction losses of the aerosol particles $\geq 3 \mu \mathrm{m}$ during their passage through the cannula, prongs, and upper airways, thereby reducing the dose of aerosol delivered to the patient's lower airway. Consequently, one guideline recommends reducing HFNC gas flow to $4 \mathrm{~L} / \mathrm{min}$ during aerosol delivery to children [45].

In contrast, during simulated adult distressed breathing, two in vitro studies reported that inhaled aerosol dose increased when gas flow decreased from 50 to 30 $\mathrm{L} / \mathrm{min}[26,27]$ and decreased when gas flow was reduced to $10 \mathrm{~L} / \mathrm{min}$ [27]. Inhaled doses were higher during distressed breathing than quiet breathing with gas flows of 30 and $50 \mathrm{~L} / \mathrm{min}$ [26, 27], but not at $10 \mathrm{~L} / \mathrm{min}$ [27]. Subsequently, Li and colleagues utilized 5 different gas flows $(5-60 \mathrm{~L} / \mathrm{min})$ and 6 different adult breathing patterns in their in vitro study and reported that the ratio of HFNC flow to patient's inspiratory flow was more important than HFNC flow alone [29]. Inhaled drug dose was higher when gas flow was set below the patient's inspiratory flow compared to gas flow exceeding inspiratory flow, and plateaued when HFNC flow was set at 50\% of the inspiratory flow [29]. These findings were consistent with a report in infants and children (Fig. 2) [30] and formed the basis for a RCT to compare albuterol delivery and effective dose at 3 different gas flow settings with a HFNC in patients with COPD or asthma [46].

Currently, no commercial device provides breathby-breath measurement of patient's inspiratory flow during HFNC. However, findings on the gas flow to patient's inspiratory flow ratio $[29,30]$ should remind clinicians to titrate gas flow settings when employing HFNC for aerosol delivery, especially for drugs such

Table 2 Comparisons of inhaled dose between VMN and jet nebulizer via HFNC

\begin{tabular}{|c|c|c|c|c|c|}
\hline \multirow[t]{2}{*}{ Publication } & \multirow{2}{*}{$\begin{array}{l}\text { Study } \\
\text { type }\end{array}$} & \multirow[t]{2}{*}{ Population } & \multirow{2}{*}{$\begin{array}{l}\text { Flow } \\
\text { (L/min) }\end{array}$} & \multicolumn{2}{|c|}{ Inhaled dose (\%) } \\
\hline & & & & $\mathrm{JN}$ & VMN \\
\hline \multirow[t]{2}{*}{ Réminiac et al., 2017 [38] } & In vivo & Infant & 8 & $0.03 \pm 0.03$ & $0.09 \pm 0.04$ \\
\hline & In vitro & & & $0.46 \pm 0.12$ & $0.52 \pm 0.23$ \\
\hline \multirow[t]{2}{*}{ Ari, 2019 [33] } & In vitro & Infant & 6 & $1.45 \pm 0.10$ & $2.35 \pm 0.30$ \\
\hline & & Pediatric & 6 & $2.46 \pm 0.10$ & $5.37 \pm 0.70$ \\
\hline Madney et al., 2019 [11] & In vivo & Adult & 5 & $7.90 \pm 3.10$ & $12.20 \pm 4.40$ \\
\hline Dugernier et al., 2017 [41] & In vivo & Adult & 30 & $1.0(0.70-2.0)$ & $3.60(2.10-4.40)$ \\
\hline
\end{tabular}

VMN vibrating mesh nebulizer, JN jet nebulizer, HFNC high-flow nasal cannula 


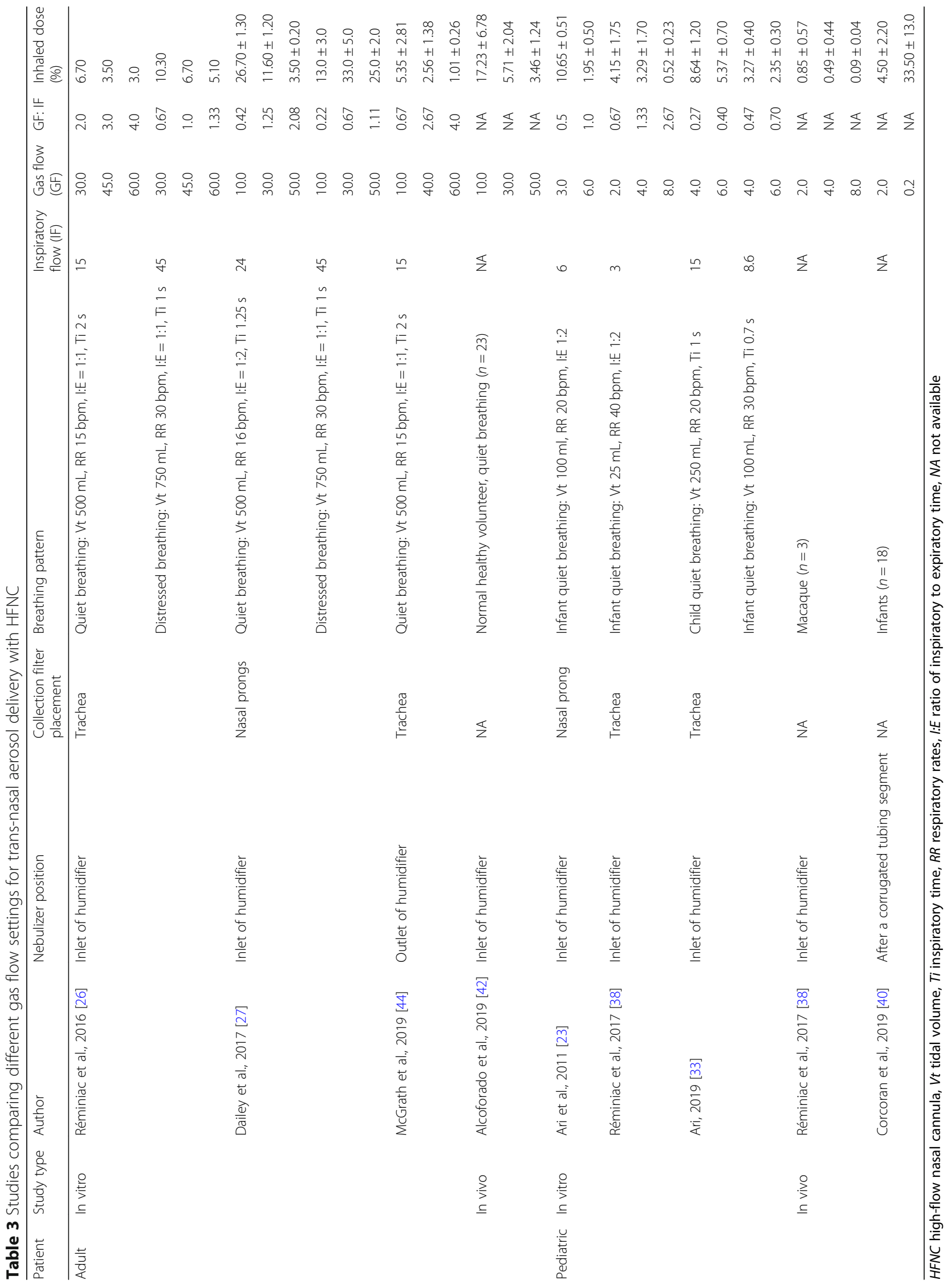




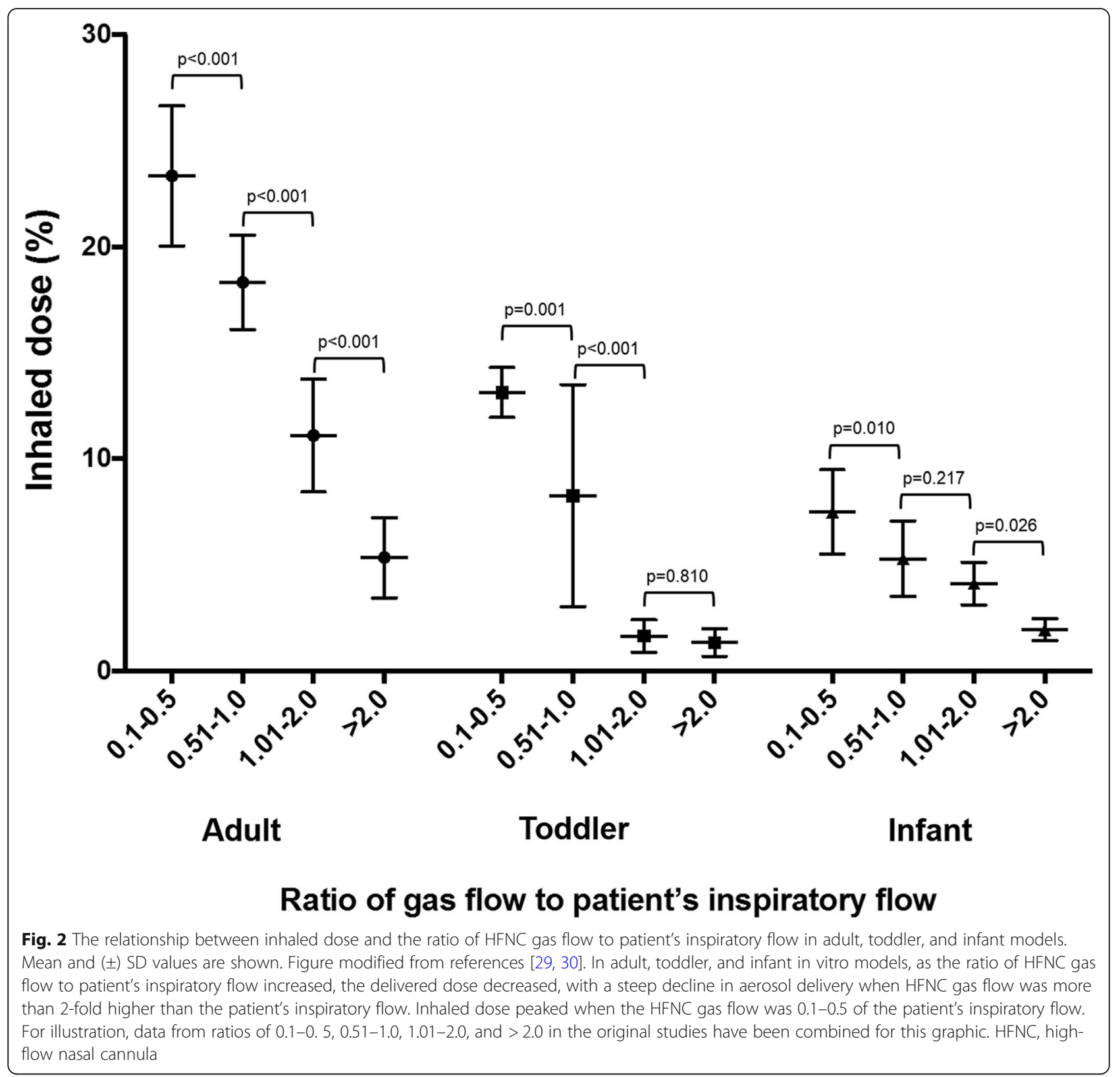

as inhaled epoprostenol that produce immediate clinical responses. In support of this recommendation, a retrospective study in patients with pulmonary hypertension and hypoxemia found that titration of gas flow at the bedside led to a better response to inhaled epoprostenol via HFNC compared with application of a constant gas flow [15].

\section{Gas density: oxygen vs heliox}

Heliox (mixture of helium and oxygen) has lower density than oxygen or air and passes through narrow circuits and airways with less turbulent flow than oxygen. Heliox is employed to reduce airway pressures and gas trapping during severe airway obstruction. A meta-analysis reported that heliox provides potential short-term benefits for children with moderate to severe croup [47]. Reducing turbulence with heliox enhances aerosol delivery with HFNC, as previously reported in bench models of mechanical ventilation [48].

In pediatric [23] and adult [27] manikins, aerosol delivery efficiency using heliox showed limited superiority over oxygen only when HFNC gas flow exceeded patient's inspiratory flow [27]. Using heliox as the carrier gas for the sole purpose of increasing aerosol therapy delivery is not cost-effective unless heliox is used to relieve dyspnea in patients with severe airway obstruction [47]. 


\section{Dry vs heated humidified gas}

In vitro and in vivo studies on mechanically ventilated patients noted that humidification reduced aerosol delivery to the lung $[49,50]$. Interestingly, during trans-nasal aerosol delivery with flows $\geq 30 \mathrm{~L} / \mathrm{min}$. Alcoforado and co-workers found 1-1.5 times higher inhaled dose with dry than humidified gas [42]. Clinically, patient discomfort and potential adverse effects with nasal administration of dry gas at flows greater than $6-10 \mathrm{~L} / \mathrm{min}$ should be considered. Moreover, turning off the humidifier for 30 min prior to aerosol administration during mechanical ventilation did not improve delivery efficiency [51]. For these reasons, the administration of dry gas in nonhumidified circuits to deliver aerosol for prolonged periods should be discouraged in clinical practice.

\section{Nebulizer placement: close to patient vs at the inlet of humidifier}

Both pediatric [25, 30] and adult [26, 39] in vitro studies reported that aerosol deposition with VMN placed at the inlet of humidifier was greater than with the nebulizer placed close to patient. The exception was in infants with extremely low gas flow $(\leq 0.25 \mathrm{~L} / \mathrm{kg} / \mathrm{min})$ where nebulizer placement closer to the patient was more efficient [30]. With the VMN placed farther away from the patient, "carrier" gas flow (including delivery gas flow and patient's inspiratory flow, combined with low tidal volume) was probably insufficient to transport aerosol to the patient before aerosol sedimentation occurred.

\section{Open mouth vs closed mouth breathing}

Open mouth breathing reduced inhaled dose compared to closed mouth breathing in the adult manikin during aerosol delivery with HFNC when gas flow was set higher than the patient's inspiratory flow [26]. This observation was consistent with a report by $\mathrm{Li}$ and co-workers in a pediatric model [37]. Interestingly, when gas flow was lower than the patient's inspiratory flow, open mouth breathing resulted in a higher inhaled dose than closed mouth breathing [37]. Perhaps aerosol carried with low gas flow collected in the nasal cavity during exhalation via mouth was drawn in with the next inhalation. In contrast, higher gas flows flushed the aerosol from the nasopharynx, thereby reducing the amount of drug available for the next inhalation [37].

\section{Delivery technique}

\section{Continuous administration using infusion pump vs unit} dose

Clinically, aerosol therapy in the acute care setting involves either (1) intermittent unit dose delivery or (2) continuous aerosol delivery. For treatment of severe airway obstruction, administration of larger doses as frequently as every 15 mins over several hours is resource and labor intensive. Initially, "continuous" aerosol delivery was employed to administer high-dose short-acting bronchodilators for prolonged periods, conventionally using a large volume JN with facemask. However, noisy JN operation and cool aerosols produced by them can irritate young patients, causing them to cry during aerosol treatment, which significantly reduces the inhaled dose [52]. In contrast, in-line placement of VMN with active humidification and HFNC provides warm and humidified gas; aerosol generation is silent and significantly improves patients' comfort and tolerance [16, 17].

Continuous administration of aerosol using VMN involves a pump feed to control rate and volume of dose emitted. At lower pump feed rates, duration between drops of medication reaching the mesh and producing aerosol is longer. Consequently, "continuous" administration has intermittent bursts of aerosol followed by periods of no aerosol. Li and colleagues reported that inhaled dose with unit dose delivery nebulizing continuously was higher than a similar nominal dose administered via infusion pump at low feed rate during the first 15 minutes of trans-nasal aerosol delivery, independent of gas flow settings [37]. This observation could be due to asynchrony of patient's inhalation with intermittent aerosol production when individual drops reach the mesh during lowrate infusion pump delivery.

\section{High vs low albuterol concentration}

In the same study, inhaled dose with albuterol in high concentration was greater than with low concentration whether given by unit dose or infusion pump, with exception of lower delivery with high gas flow $(2 \mathrm{~L} / \mathrm{kg} / \mathrm{min})$ during infusion pump delivery [37].

\section{Aerosol generation: breathing synchronized vs continuous}

Continuous generation of aerosol by nebulizers JN or $\mathrm{VMN}$, in-line with HFNC, results in wastage to the atmosphere during the expiratory phase. Synchronized aerosol generation with patient's spontaneous breathing increases inhaled dose during both invasive [53] and noninvasive ventilation $[54,55]$. With a prototype breath-synchronized VMN, Li and colleagues reported inhaled dose was higher with breath-synchronized versus continuous aerosol generation when placed close to the patient with HFNC gas flow $\geq 10 \mathrm{~L} / \mathrm{min}$. However, when placed at the inlet of the humidifier, breath-synchronized VMN generated a higher inhaled dose than continuous operation only when HFNC gas flow was below 50\% of patient's inspiratory flow [39]. This finding is likely explained by storage of the 
aerosol in the HFNC circuit during the exhalation phase. The optimal ratio of HFNC gas flow to patient's inspiratory flow that generates the highest inhaled dose depends on the balance between aerosol storage and gravitational sedimentation in the circuit.

\section{Other aerosol delivery methods during HFNC treatment}

Alternatives to placing nebulizers in-line to administer aerosol during HFNC include placing the nebulizer with mouthpiece/mask over the nasal cannula; or discontinuing HFNC to administer aerosol by conventional methods [8].

Nebulizer or MDI+spacer with vs without concurrent HFNC Administration of conventional aerosol devices (JN, VMN, or MDI with spacer) using mask/mouthpiece during HFNC reduced inhaled dose to a level that was only $6-50 \%$ of the inhaled dose with those devices alone without concurrent HFNC [32, 34], as high velocity gas from HFNC disperses aerosol away from the upper airway.

\section{Aerosol delivery via HFNC vs conventional aerosol delivery}

Aerosol delivery via $\mathrm{HFNC}$ at high gas flows $(50 \mathrm{~L} / \mathrm{min}$ for adult and $2 \mathrm{~L} / \mathrm{kg} / \mathrm{min}$ for children) generated similar inhaled dose as a JN and mask [33, 37, 38], but lower inhaled dose than VMN with mask [32, 33]. However, at lower gas flows $(0.25-0.5 \mathrm{~L} / \mathrm{kg} / \mathrm{min}$ for pediatrics), the inhaled dose via HFNC was higher than that with VMN and mask [37] and 2-3-fold higher than that with JN and mask (Table 4) [37, 38].
Other considerations in the in vitro studies Airway model and placement of collecting filter

During in vitro studies, aerosol deposition was lower with collecting filter placed at "trachea" level $[26,32]$ than with filter placed distal to the nasal cannula (Table 5) [27]. This is because the anatomical volumes and structures of the upper airway serve as baffles upon which aerosol impacts, and the "exhalable" fraction of aerosol that stays in the trachea and upper airway at the end of inspiration is exhaled with the filter placed at "trachea." Thus, results from in vitro studies especially with collecting filter placed close to nasal cannula could overestimate the actual aerosol drug delivery in vivo [38].

\section{Breathing profiles}

No studies have fully characterized patients' breathing profiles during HFNC treatment. Breathing parameters in the in vitro studies do not truly reflect patients' breathing patterns, which vary breath by breath in individual and also display inter- and intra-patient variability [56].

\section{Safety of trans-nasal aerosol on the nasal epithelium}

The potential toxicity or harms of aerosol deposition in the nasopharynx during HFNC are unknown. For example, hypertonic saline, tobramycin solution, and dry air decrease ciliary beat frequency [57]. Elucidation of in vivo nasal toxicity with each drug formulation used with HFNC is necessary because many drugs are

Table 4 In vitro studies compared aerosol delivery via HFNC vs conventional aerosol device (JN or VMN with mask)

\begin{tabular}{|c|c|c|c|c|c|c|}
\hline \multirow[t]{2}{*}{ Author, year } & \multirow[t]{2}{*}{ Patient } & \multirow{2}{*}{$\begin{array}{l}\text { HFNC gas flow } \\
\text { setting (L/min) }\end{array}$} & \multirow{2}{*}{$\begin{array}{l}\text { Flow setting } \\
\text { for conventional } \\
\text { nebulizer }(\mathrm{L} / \mathrm{min})\end{array}$} & \multicolumn{3}{|l|}{ Inhaled dose (\%) } \\
\hline & & & & Aerosol delivery via HFNC & JN with mask & VMN with mask \\
\hline \multirow[t]{4}{*}{ Ari, 2019 [33] } & Child & 6 & 6 & $5.37 \pm 0.7$ & $5.76 \pm 0.10$ & $11.26 \pm 1.90$ \\
\hline & & 4 & & $8.64 \pm 1.2$ & & \\
\hline & Infant & 6 & 6 & $2.35 \pm 0.3$ & $3.83 \pm 0.50$ & $7.20 \pm 0.60$ \\
\hline & & 4 & & $3.27 \pm 0.4$ & & \\
\hline \multirow[t]{2}{*}{ Li et al., 2019 [37] } & Child & 25 & 8 & $2.84 \pm 0.20$ & $2.99 \pm 0.41$ & $3.65 \pm 0.16$ \\
\hline & & 3.75 & 2 & $11.57 \pm 0.43$ & NA & $3.82 \pm 0.07$ \\
\hline \multirow[t]{6}{*}{ Réminiac et al., 2017 [38] } & Infant & 8 & 6 & $0.09 \pm 0.04$ & $0.71 \pm 0.23$ & NA \\
\hline & & 4 & & $0.49 \pm 0.44$ & & \\
\hline & & 2 & & $0.85 \pm 0.57$ & & \\
\hline & Toddler & 8 & 6 & $0.52 \pm 0.33$ & $1.66 \pm 0.06$ & NA \\
\hline & & 4 & & $3.29 \pm 1.70$ & & \\
\hline & & 2 & & $4.15 \pm 1.75$ & & \\
\hline \multirow[t]{2}{*}{ Bennett et al., 2019 [32] } & Adult & 50 & 8 & $6.81 \pm 0.45$ & $9.07 \pm 0.26$ & NA \\
\hline & & & 6 & NA & NA & $36.21 \pm 0.78$ \\
\hline
\end{tabular}


Table 5 Comparisons of the results with collecting filter placed at trachea vs nasal cannula in adult in vitro studies

\begin{tabular}{|c|c|c|c|c|c|}
\hline \multirow[t]{2}{*}{ Studies } & \multirow[t]{2}{*}{ Population } & \multirow[t]{2}{*}{ Breathing pattern } & \multirow{2}{*}{$\begin{array}{l}\text { HFNC flow } \\
(\mathrm{L} / \mathrm{min})\end{array}$} & \multicolumn{2}{|c|}{ Inhaled dose (\%) } \\
\hline & & & & Trachea & Nasal cannula \\
\hline \multirow[t]{3}{*}{ Réminiac et al., 2016 [26], and Dailey et al., 2017 [27] } & \multirow[t]{3}{*}{ Adult } & \multirow{3}{*}{$\begin{array}{l}\text { Distressed breathing } \\
\text { Vt } 750 \mathrm{~mL} \text {, RR } 30 \mathrm{bpm} \text {, l:E = 1:1, } \\
\text { Ti } 1 \mathrm{~s} \text {, inspiratory flow } \\
45 \mathrm{~L} / \mathrm{min}\end{array}$} & 30 & 10.3 & $13.0 \pm 3.0$ \\
\hline & & & 45 & 6.7 & $33.0 \pm 5.0$ \\
\hline & & & 60 & 5.1 & $25.0 \pm 2.0$ \\
\hline Bennett et al., 2019 [32], and Dailey, 2017 [27] & Adult & $\begin{array}{l}\text { Quiet breathing: Vt } 500 \mathrm{~mL} \text {, } \\
\text { RR } 15 \mathrm{bpm}, \mathrm{l}: \mathrm{E}=1: 1, \mathrm{Ti} 2 \mathrm{~s} \text {, } \\
\text { inspiratory flow } 15 \mathrm{~L} / \mathrm{min}\end{array}$ & 10 & $5.4 \pm 2.8$ & $26.7 \pm 1.3$ \\
\hline
\end{tabular}

HFNC high flow nasal cannula, $V t$ tidal volume, $R R$ respiratory rates, $T i$ inspiratory time, l:E ratio of inspiratory time to expiratory time

approved for delivery by nebulizer via facemask, with consequent potential for nasal exposure.

\section{Environmental contamination}

During aerosol delivery via HFNC, aerosol leakage from the nasal cannula to the environment combines with aerosol exhaled by patients into the atmosphere. Environmental fugitive emissions decreased as HFNC gas flow increased [44], likely due to turbulence effects of the high velocity gas leading to high impactive losses of aerosol en route. Bedside clinicians should employ personal protection during trans-nasal aerosol delivery, particularly when high-risk medications are administered.

\section{Summary}

Among these in vitro studies, the ratio of HFNC gas flow to patient's inspiratory flow was critical; optimal inhaled dose was achieved when HFNC gas flow was set $50 \%$ of inspiratory flow. VMN used with HFNC generated a higher inhaled dose than JN. VMN placed at the inlet of humidifier generated a greater inhaled dose than VMN placed closer to the patient. When using dry gas or heliox as HFNC carrier gas, compared with humidified gas or oxygen, respectively, the inhaled dose was higher only when HFNC gas flow exceeded patient's inspiratory flow. However, patient's inability to tolerate dry gas or the high cost of using heliox particularly for prolonged duration is a deterrent to their routine use. Removing HFNC to use a conventional aerosol device did not improve drug delivery, and placing a conventional aerosol device via mask/mouthpiece concurrent with HFNC reduced drug delivery.

\section{Clinical implications and recommendations: trans- nasal aerosol delivery strategies for different patients}

Table 6 provides recommendations on trans-nasal pulmonary aerosol delivery with HFNC, to help optimize aerosol delivery concurrent with HFNC.

\section{Asthma exacerbation}

During status asthmaticus, HFNC improves work of breathing and reduces carbon dioxide retention [2, 58,
59]. The comfort of aerosol delivery via HFNC makes it an ideal option, particularly for young children $[8,16$, 17]. High gas flow setting has some benefits, but it impedes aerosol delivery to the lung. Reduction in HFNC flow from 2.0 to $0.5 \mathrm{~L} / \mathrm{kg} / \mathrm{min}$ resulted in a $21 \%$ increase in patient's work of breathing [60]. However, the inhaled dose by trans-nasal aerosol delivery at the lower gas flow increased by 3 - to 12 -fold [30, 37, 38, 40]. Thus, reducing the HFNC flow improves aerosol delivery at the slight risk of losing breathing support for short periods, while using unit doses could shorten the duration of treatment. Delivery of $1 \mathrm{~mL}$ requires $2-4 \mathrm{~min}$; reducing the gas flow for such a short period should not significantly interfere with work of breathing. We caution that when HFNC flow is reduced, the patient should be closely monitored and $\mathrm{F}_{\mathrm{I}} \mathrm{O}_{2}$ increased if needed to maintain a target $\mathrm{SpO}_{2}$ [61].

Patients with severe asthma often require larger than conventional bronchodilator doses. Multiple unit doses are delivered more frequently, requiring intensive use of staff resources. Bronchodilators could be delivered using HFNC with an infusion pump and prepared syringe of albuterol. In this scenario, a higher dose could be delivered to the lung by utilizing a relatively low gas flow and a slightly higher nominal dose compared to conventional bronchodilator aerosol delivery techniques [37].

\section{Stable COPD and COPD exacerbation}

HFNC is increasingly utilized for patients with COPD for its effects of washing out dead space and reducing work of breathing $[2,62]$. Long-term use of HFNC could reduce the frequency and duration of COPD exacerbations and improve patient's quality of life [63, 64]. In those studies with stable COPD, HFNC flow was set at $20-25 \mathrm{~L} / \mathrm{min}[63,64]$ due to the patient's low inspiratory flow demand. HFNC gas flow of $15-20 \mathrm{~L} / \mathrm{min}$ with a standard dose of $2.5 \mathrm{mg}$ albuterol is sufficient to elicit bronchodilator effects [12].

During exacerbation of COPD, higher than usual patient's inspiratory flow demand requires an increase of flow setting with HFNC. In 12 hypercapnic patients with COPD initially treated with noninvasive ventilation, Rittayamai and colleagues achieved similar work of 


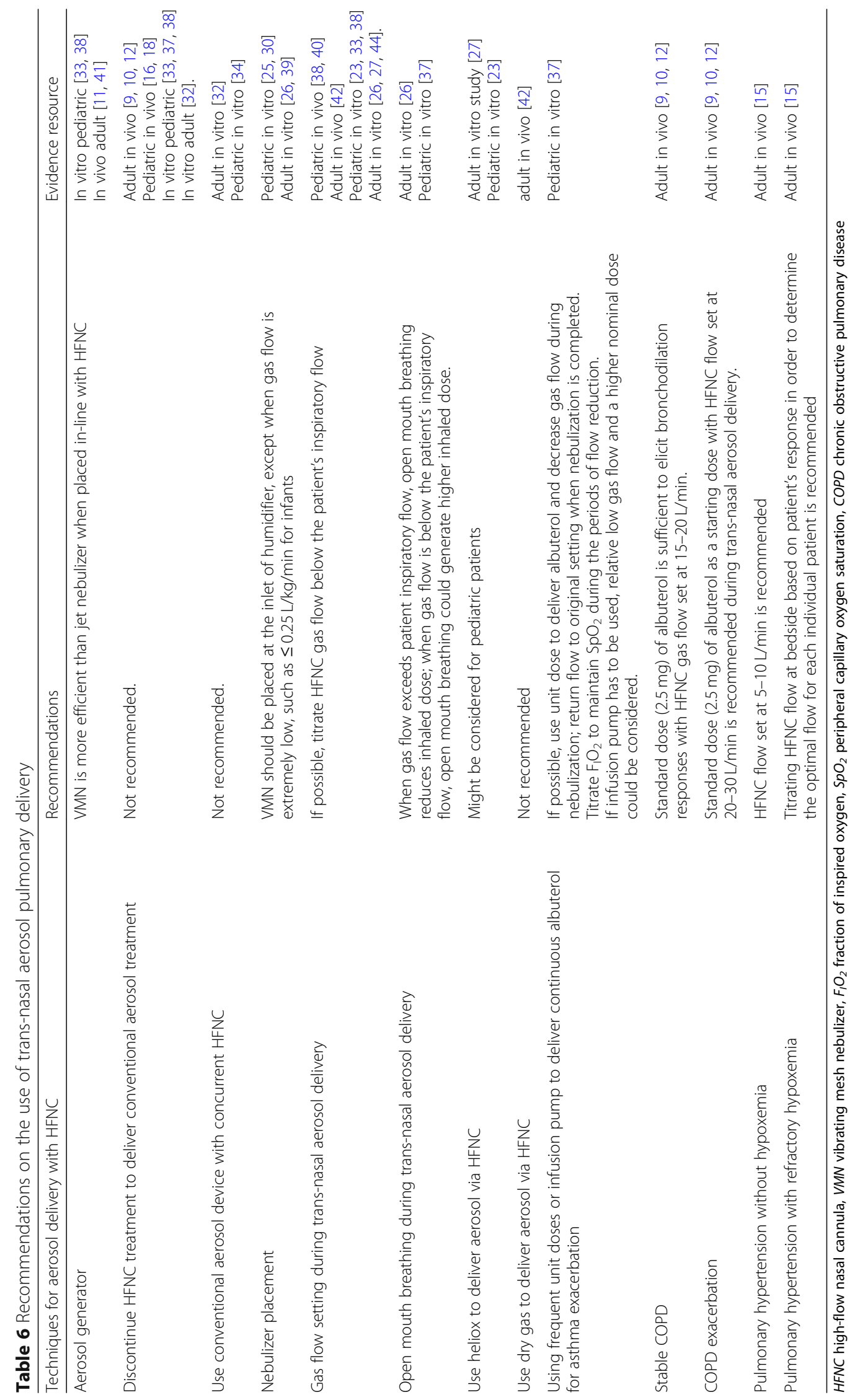


breathing with HFNC flow set at $30 \mathrm{~L} / \mathrm{min}$ [65]. Discontinuing HFNC to use a facemask significantly increased patients' breathing efforts [66]. Therefore, HFNC should not be interrupted to use mask/mouthpiece with $\mathrm{JN}$ when acutely ill patients with COPD require aerosol treatments. In this setting, it is appropriate to deliver aerosol via $\mathrm{HFNC}$ at $20-30 \mathrm{~L} / \mathrm{min}$ flow.

\section{Pulmonary hypertension with/without hypoxemia}

In patients with pulmonary hypertension, prolonged continuous inhalation of aerosolized epoprostenol with HFNC is convenient and comfortable for the patient. In the absence of concomitant hypoxemia and with low inspiratory flow demand, low gas flows with HFNC (5-10 L/min) could optimize delivery of inhaled epoprostenol to patients with pulmonary hypertension $[15,27,29,42]$.

When patients with pulmonary hypertension have concomitant hypoxemia, higher gas flow and $\mathrm{F}_{\mathrm{I}} \mathrm{O}_{2}$ are required to improve oxygenation by avoiding air entrainment and generating some positive end-expiratory pressure $[58,66]$. However, high gas flows reduce trans-nasal delivery of inhaled epoprostenol with a potential loss of efficacy because there is a linear correlation of inhaled dose with improvement in oxygenation [20]. A practical solution would be to titrate HFNC gas flow at the bedside to pulmonary arterial pressure and/or oxygenation [15]. This approach could determine optimal setting for individual patient, based on immediate responses to inhaled epoprostenol.

\section{Summary}

Patients, who did not require HFNC for administering high $\mathrm{F}_{\mathrm{I}} \mathrm{O}_{2}$ and who could tolerate reduced gas flow for short periods, could be benefited by decreasing HFNC gas flow to relatively low settings, such as $15-20 \mathrm{~L} / \mathrm{min}$ for stable adult patients, $20-30 \mathrm{~L} / \mathrm{min}$ during COPD/ asthma exacerbation among adults, and $0.25 \mathrm{~L} / \mathrm{kg} / \mathrm{min}$ for children with asthma. Employing unit doses with high drug concentration could shorten the duration for which flow was reduced. After administration of the unit dose, HFNC gas flow should be returned to its previous setting. For patients receiving HFNC therapy mainly for relief of hypoxemia and who simultaneously require inhaled epoprostenol to improve oxygenation, HFNC gas flow should be carefully titrated at the bedside based on patients' response to both inhaled epoprostenol and gas flow.

\section{Future directions}

More clinical studies are needed to validate the in vitro findings, such as the impact of gas flow on aerosol delivery via HFNC, and the effective dose at those flow settings [46]. Clinical studies of patient safety are also warranted, particularly the potential for toxicity or harm with off-label use of medication inhaled via HFNC. The use of submicrometer droplets combined with condensational growth technology has shown significant improvements of inhaled dose during trans-nasal aerosol delivery in vitro [67], and its application in clinical practice is awaited.

\section{Conclusion}

Trans-nasal pulmonary aerosol delivery via HFNC is a promising method for continuous administration of medication for prolonged periods, especially for children. However, clinicians must consider the features and limitations of the device, and the patient's disease severity. There is increasing evidence to support clinical efficacy and safety of trans-nasal pulmonary aerosol delivery via HFNC. Prospective, well-designed studies in appropriate populations of patients are needed to establish the efficacy of this mode of aerosol administration. We provide practical recommendations for employing trans-nasal pulmonary aerosol delivery via HFNC in acutely ill patients.

\section{Abbreviations}

HFNC: High-flow nasal cannula; RCT: Randomized controlled trials; ICU: Intensive care unit; COPD: Chronic obstructive pulmonary disease; $\mathrm{FEV}_{1}$ : Forced expiratory volume in the first second; VMN: Vibrating mesh nebulizer; MDI: Metered dose inhaler; JN: Jet nebulizers; $\mathrm{PaO}_{2}$ : Partial pressure of arterial oxygen; $\mathrm{SpO}_{2}$ : Peripheral capillary oxygen saturation; $\mathrm{F}_{1} \mathrm{O}_{2}$ : Fraction of inspired oxygen; Cl: Confidence interval

\section{Authors' contributions}

$R D$, JBF, and $J L$ conceived of the idea. $J L$ performed literature search and drafted the manuscript; RD supervised the process. RD, JL, JBF, and RM provided critical revision on the manuscript. All authors reviewed and approved the final version.

\section{Funding}

Not applicable.

\section{Availability of data and materials \\ Not applicable.}

Ethics approval and consent to participate Not applicable.

\section{Consent for publication \\ Not applicable.}

\section{Competing interests}

Dr. Dhand reports remuneration from GSK Pharmaceuticals, BoehringerIngelheim, Bayer, Mylan, Teva, and Astra-Zeneca Pharmaceuticals outside the submitted work. Dr. Fink is Chief Science Officer for Aerogen Pharma Corp, San Mateo, CA, USA. Dr. MacLoughlin is the Senior Manager Science for Aerogen Ltd., Galway, Ireland. Dr. Li declares to receive research funding from Fisher \& Paykel Healthcare, The Daniel and Ada Rice Foundation. None of the companies had a role in the conception of this review, in the literature search or interpretation, in the writing of the manuscript, or in the decision to publish the results.

\section{Author details}

'Division of Respiratory Care, Department of Cardiopulmonary Sciences, Rush University Medical Center, 1620 W Harrison St, Tower LL1202, Chicago, IL 60612, USA. ${ }^{2}$ Aerogen Pharma Corp, San Mateo, CA, USA. ${ }^{3}$ Aerogen, Galway, Ireland. ${ }^{4}$ Department of Medicine, University of Tennessee Graduate School of Medicine, Knoxville, TN, USA. 
Received: 1 March 2020 Accepted: 27 July 2020

Published online: 17 August 2020

\section{References}

1. Rochwerg B, Granton D, Wang DX, Helviz Y, Einav S, Frat JP, et al. High flow nasal cannula compared with conventional oxygen therapy for acute hypoxemic respiratory failure: a systematic review and meta-analysis. Intensive Care Med. 2019;45(5):563-72.

2. Li J, Jing GQ, Scott JB. Year in review 2019: high-flow nasal cannula (HFNC) oxygen therapy for adult patients. Respir Care. 2020;65(4):545-57.

3. Kang H, Zhao Z, Tong Z. Effect of high-flow nasal cannula oxygen therapy in immunocompromised subjects with acute respiratory failure. Respir Care. 2020;65(3):369-76.

4. Zhu Y, Yin $H$, Zhang $R$, Ye $X$, Wei J. High-flow nasal cannula oxygen therapy versus conventional oxygen therapy in patients after planned extubation: a systematic review and meta-analysis. Crit Care. 2019;23(1):180.

5. Fong KM, Au SY, Ng GWY. Preoxygenation before intubation in adult patients with acute hypoxemic respiratory failure: a network meta-analysis of randomized trials. Crit Care. 2019;23(1):319.

6. Dugernier J, Reychler G, Vecellio L, Ehrmann S. Nasal high-flow nebulization for lung drug delivery: theoretical, experimental, and clinical application. J Aerosol Med Pulm Drug Deliv. 2019;32(6):341-51.

7. Ari A. Aerosol drug delivery through high flow nasal cannula. Curr Pharm Biotechnol. 2017;18(11):877-82.

8. Miller AG, Gentle MA, Tyler LM, Napolitano N. High-flow nasal cannula in pediatric patients: a survey of clinical practice. Respir Care. 2018;63(7):894-9.

9. Bräunlich J, Wirtz H. Oral versus nasal high-flow bronchodilator inhalation in chronic obstructive pulmonary disease. J Aerosol Med Pulm Drug Deliv. 2018;31(4):248-54.

10. Réminiac F, Vecellio L, Bodet-Contentin L, Gissot V, Le Pennec D, Salmon Gandonniere C, et al. Nasal high-flow bronchodilator nebulization: a randomized cross-over study. Ann Intensive Care. 2018;8(1):128.

11. Madney YM, Fathy M, Elberry AA, Rabea H, Abdelrahim ME. Aerosol delivery through an adult high-flow nasal cannula circuit using low-flow oxygen. Respir Care. 2019;64(4):453-61.

12. Li J, Zhao M, Hadeer M, Luo J, Fink JB. Dose response to transnasal pulmonary administration of bronchodilator aerosols via nasal high-flow therapy in adults with stable chronic obstructive pulmonary disease and asthma. Respiration. 2019;98(5):401-9.

13. Ammar MA, Sasidhar M, Lam SW. Inhaled epoprostenol through noninvasive routes of ventilator support systems. Ann Pharmacother. 2018 52(12):1173-81.

14. Li J, Harnois LJ, Markos B, Roberts KM, Al Homoud S, Liu J, et al. Epoprostenol delivered via high flow nasal cannula for ICU subjects with severe hypoxemia comorbid with pulmonary hypertension or right heart dysfunction. Pharmaceutics. 2019;11(6):281.

15. Li J, Gurnani PK, Roberts KM, Fink JB, Vines D. The clinical impact of flow titration on epoprostenol delivery via high flow nasal cannula for icu patients with pulmonary hypertension or right ventricular dysfunction: a retrospective cohort comparison study. J Clin Med. 2020;9(2):464.

16. Morgan SE, Mosakowski S, Solano P, Hall JB, Tung A. High-flow nasal cannula and aerosolized beta agonists for rescue therapy in children with bronchiolitis: a case series. Respir Care. 2015;60(9):e161-5.

17. Valencia-Ramos J, Miras A, Cilla A, Ochoa C, Arnaez J. Incorporating a nebulizer system into high-flow nasal cannula improves comfort in infants with bronchiolitis. Respir Care. 2018;63(7):886-93.

18. Al-Subu AM, Nguyen VT, AlAli Y, Yngsdal-Krenz RA, Lasarev MR, Eldridge MW, et al. Feasibility of aerosol bronchodilators delivery through high-flow nasal cannula in pediatric subjects with respiratory distress. Respir Care. 2020:[Epub ahead of print].

19. Baudin F, Buisson A, Vanel B, Massenavette B, Pouyau R, Javouhey E. Nasal high flow in management of children with status asthmaticus: a retrospective observational study. Ann Intensive Care. 2017;7(1):55.

20. Fuller BM, Mohr NM, Skrupky L, Fowler S, Kollef MH, Carpenter CR. The use of inhaled prostaglandins in patients with ards: a systematic review and meta-analysis. Chest. 2015;147(6):1510-22.

21. Hill NS, Preston IR, Roberts KE. Inhaled therapies for pulmonary hypertension. Respir Care. 2015;60(6):794-802.

22. Bhashyam AR, Wolf MT, Marcinkowski AL, Saville A, Thomas K, Carcillo JA, et al. Aerosol delivery through nasal cannulas: an in vitro study. J Aerosol Med Pulm Drug Deliv. 2008;21(2):181-8.
23. Ari A, Harwood R, Sheard M, Dailey P, Fink JB. In vitro comparison of heliox and oxygen in aerosol delivery using pediatric high flow nasal cannula. Pediatr Pulmonol. 2011;46(8):795-801.

24. Perry SA, Kesser KC, Geller DE, Selhorst DM, Rendle JK, Hertzog JH. Influences of cannula size and flow rate on aerosol drug delivery through the vapotherm humidified high-flow nasal cannula system. Pediatr Crit Care Med. 2013;14(5):e250-6.

25. Sunbul FS, Fink JB, Harwood R, Sheard MM, Zimmerman RD, Ari A. Comparison of hfnc, bubble cpap and sipap on aerosol delivery in neonates: an in-vitro study. Pediatr Pulmonol. 2015;50(11):1099-106.

26. Réminiac F, Vecellio L, Heuze-Vourc'h N, Petitcollin A, Respaud R, Cabrera $M$, et al. Aerosol therapy in adults receiving high flow nasal cannula oxygen therapy. J Aerosol Med Pulm Drug Deliv. 2016;29(2): 134-41.

27. Dailey PA, Harwood R, Walsh K, Fink JB, Thayer T, Gagnon G, et al. Aerosol delivery through adult high flow nasal cannula with heliox and oxygen. Respir Care. 2017;62(9):1186-92.

28. Madney YM, Fathy M, Elberry AA, Rabea H, Abdelrahim MEA. Abdelrahim M. Nebulizers and spacers for aerosol delivery through adult nasal cannula at low oxygen flow rate: An in-vitro study. J Drug Delivery Sci Technol 2017;39:260-265.

29. Li J, Gong L, Fink JB. The ratio of nasal cannula gas flow to patient inspiratory flow on trans-nasal pulmonary aerosol delivery for adults: an in vitro study. Pharmaceutics. 2019;11(5):225.

30. Li J, Gong L, Ari A, Fink JB. Decrease the flow setting to improve trans-nasal pulmonary aerosol delivery via "high-flow nasal cannula" to infants and toddlers. Pediatr Pulmonol. 2019;54(6):914-21.

31. Bennett $G$, Joyce M, Sweeney L, MacLoughlin R. In vitro study of the effect of breathing pattern on aerosol delivery during high-flow nasal therapy. Pulmonary Therapy. 2019;5(1):43-54.

32. Bennett G, Joyce M, Fernandez EF, MacLoughlin R. Comparison of aerosol delivery across combinations of drug delivery interfaces with and without concurrent high-flow nasal therapy. Intensive Care Med Exp. 2019;7(1):20

33. Ari A. Effect of nebulizer type, delivery interface, and flow rate on aerosol drug delivery to spontaneously breathing pediatric and infant lung models. Pediatr Pulmonol. 2019;54(11):1735-41.

34. Alalwan MA, Fink JB, Ari A. In vitro evaluation of aerosol drug delivery with and without high flow nasal cannula in children. Pediatr Pulmonol. 2019; 54(12):1968-73.

35. Valencia-Ramos J, Arnaez J, Benito JM, Miras A, Ochoa C, Beltran S. A comparative in vitro study of standard facemask jet nebulization and high-flow nebulization in bronchiolitis. Exp Lung Res. 2019;45(1-2):1321.

36. Wallin M, Tang P, Chang RYK, Yang M, Finlay WH, Chan HK. Aerosol drug delivery to the lungs during nasal high flow therapy: an in vitro study. BMC Pulm Med. 2019;19(1):42.

37. Li J, Wei W, Fink JB. In vitro comparison of unit dose vs infusion pump administration of albuterol via high-flow nasal cannula in toddlers. Pediatr Pulmonol. 2019;55(2):322-9.

38. Réminiac F, Vecellio L, Loughlin RM, Le Pennec D, Cabrera M, Vourc'h $\mathrm{NH}$, et al. Nasal high flow nebulization in infants and toddlers: an in vitro and in vivo scintigraphic study. Pediatr Pulmonol. 2017;52(3): 337-44.

39. Li J, Wu W. Fink JB. In vitro comparison between inspiration synchronized and continuous vibrating mesh nebulizer during trans-nasal aerosol delivery. Intensive Care Med Exp. 2020;8(1):6.

40. Corcoran TE, Saville A, Adams PS, Johnston DJ, Czachowski MR, Domnina YA, et al. Deposition studies of aerosol delivery by nasal cannula to infants. Pediatr Pulmonol. 2019;54(8):1319-25.

41. Dugernier J, Hesse M, Jumetz T, Bialais E, Roeseler J, Depoortere V, et al. Aerosol delivery with two nebulizers through high-flow nasal cannula: a randomized cross-over single-photon emission computed tomographycomputed tomography study. J Aerosol Med Pulm Drug Deliv. 2017;30(5): 349-58.

42. Alcoforado L, Ari A, Barcelar JM, Brandao SCS, Fink JB, de Andrade AD. Impact of gas flow and humidity on trans-nasal aerosol deposition via nasal cannula in adults: a randomized cross-over study. Pharmaceutics. 2019;11(7): 320.

43. Kendrick AH, Smith EC, Denyer J. Nebulizers--fill volume, residual volume and matching of nebulizer to compressor. Respir Med. 1995;89(3):157-9. 
44. McGrath JA, O'Toole C, Bennett G, Joyce M, Byrne MA, MacLoughlin R. Investigation of fugitive aerosols released into the environment during high-flow therapy. Pharmaceutics. 2019;11(6):254.

45. Ministry of Health in New South Wales Australia. Humidified high flow nasal cannula oxygen guideline for metropolitan paediatric wards and eds: Http://www1.Health.Nsw.Gov.Au/pds/activepdsdocuments/gl2016_004.Pdf Accessed 7 Feb 2020.

46. Li J, Luo J, Chen Y, Xie L, Fink JB. Effects of flow rate on transnasal pulmonary aerosol delivery of bronchodilators via high-flow nasal cannula for patients with copd and asthma: protocol for a randomised controlled trial. BMJ Open. 2019;9(6):e028584.

47. Moraa I, Sturman N, McGuire TM, van Driel ML. Heliox for croup in children. Cochrane Database Syst Rev. 2018;10:CD006822.

48. Goode ML, Fink JB, Dhand R, Tobin MJ. Improvement in aerosol delivery with helium-oxygen mixtures during mechanical ventilation. Am J Respir Crit Care Med. 2001;163(1):109-14.

49. Fink JB, Dhand R, Duarte AG, Jenne JW, Tobin MJ. Aerosol delivery from a metered-dose inhaler during mechanical ventilation. An in vitro model. Am J Respir Crit Care Med. 1996:154(2 Pt 1):382-7.

50. Ari A, Areabi H, Fink JB. Evaluation of aerosol generator devices at 3 locations in humidified and non-humidified circuits during adult mechanical ventilation. Respir Care. 2010;55(7):837-44.

51. Lin HL, Fink JB, Zhou Y, Cheng YS. Influence of moisture accumulation in inline spacer on delivery of aerosol using metereddose inhaler during mechanical ventilation. Respir Care. 2009;54(10): 1336-41.

52. Amirav I, Newhouse MT, Minocchieri S, Castro-Rodriguez JA, Schuepp KG. Factors that affect the efficacy of inhaled corticosteroids for infants and young children. J Allergy Clin Immunol. 2010;125(6):1206-11.

53. Miller DD, Amin MM, Palmer LB, Shah AR, Smaldone GC. Aerosol delivery and modern mechanical ventilation: in vitro/in vivo evaluation. Am J Respir Crit Care Med. 2003;168(10):1205-9.

54. Michotte JB, Staderini E, Le Pennec D, Dugernier J, Rusu R, Roeseler J, et al. In vitro comparison of a vibrating mesh nebulizer operating in inspiratory synchronized and continuous nebulization modes during noninvasive ventilation. J Aerosol Med Pulm Drug Deliv. 2016;29(4): 328-36.

55. Michotte JB, Staderini E, Aubriot AS, Jossen E, Dugernier J, Liistro G, et al. Pulmonary drug delivery following continuous vibrating mesh nebulization and inspiratory synchronized vibrating mesh nebulization during noninvasive ventilation in healthy volunteers. J Aerosol Med Pulm Drug Deliv. 2018:31(1):33-41

56. Mauri T, Spinelli E, Dalla Corte F, Scotti E, Turrini C, Lazzeri M, et al. Noninvasive assessment of airflows by electrical impedance tomography in intubated hypoxemic patients: an exploratory study. Ann Intensive Care. 2019;9(1):83

57. Boon $M$, Jorissen $M$, Jaspers $M$, Augustijns $P$, Vermeulen $F L$, Proesmans $M$ et al. The influence of nebulized drugs on nasal ciliary activity. J Aerosol Med Pulm Drug Deliv. 2016;29(4):378-85.

58. Mauri T, Turrini C, Eronia N, Grasselli G, Volta CA, Bellani G, et al. Physiologic effects of high-flow nasal cannula in acute hypoxemic respiratory failure. Am J Respir Crit Care Med. 2017;195(9):1207-15.

59. Bräunlich J, Köhler M, Wirtz H. Nasal highflow improves ventilation in patients with COPD. Int J Chron Obstruct Pulmon Dis. 2016;11: 1077-85.

60. Weiler T, Kamerkar A, Hotz J, Ross PA, Newth CJL, Khemani RG. The relationship between high flow nasal cannula flow rate and effort of breathing in children. J Pediatr. 2017;189:66-71 e63.

61. Chikata Y, Ohnishi S, Nishimura M. Humidity and inspired oxygen concentration during high-flow nasal cannula therapy in neonatal and infant lung models. Respir Care. 2017;62(5):532-7.

62. Pisani L, Astuto M, Prediletto I, Longhini F. High flow through nasal cannula in exacerbated copd patients: a systematic review. Pulmonology. 2019;25(6): 348-54.

63. Rea H, McAuley S, Jayaram L, Garrett J, Hockey H, Storey L, et al. The clinical utility of long-term humidification therapy in chronic airway disease. Respir Med. 2010;104(4):525-33.

64. Braunlich J, Dellweg D, Bastian A, Budweiser S, Randerath W, Triche D, et al. Nasal high-flow versus noninvasive ventilation in patients with chronic hypercapnic copd. Int J Chron Obstruct Pulmon Dis. 2019;14: $1411-21$.
65. Rittayamai N, Phuangchoei P, Tscheikuna J, Praphruetkit N, Brochard L. Effects of high-flow nasal cannula and non-invasive ventilation on inspiratory effort in hypercapnic patients with chronic obstructive pulmonary disease: a preliminary study. Ann Intensive Care. 2019;9(1):122.

66. Chanques G, Riboulet F, Molinari N, Carr J, Jung B, Prades A, et al. Comparison of three high flow oxygen therapy delivery devices: a clinical physiological cross-over study. Minerva Anestesiol. 2013;79(12): 1344-55.

67. Golshahi L, Longest PW, Azimi M, Syed A, Hindle M. Intermittent aerosol delivery to the lungs during high-flow nasal cannula therapy. Respir Care. 2014;59(10):1476-86.

\section{Publisher's Note}

Springer Nature remains neutral with regard to jurisdictional claims in published maps and institutional affiliations. 